\title{
ChemComm
}

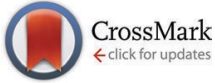

Cite this: Chem. Commun., 2015, 51, 17237

Received 14th September 2015, Accepted 2nd October 2015

DOI: $10.1039 / c 5 c c 07680 c$

www.rsc.org/chemcomm

\section{A double hetero[4] helicene composed of two phenothiazines: synthesis, structural properties, and cationic states $\uparrow$}

\author{
Daisuke Sakamaki, ${ }^{* a}$ Daisuke Kumano, ${ }^{b}$ Eiji Yashima $^{\mathrm{b}}$ and Shu Seki ${ }^{\mathrm{a}}$
}

\begin{abstract}
A novel double hetero[4]helicene consisting of two phenothiazines (1) has been synthesized. The racemization barrier of 1 is high enough for optical separation. We successfully obtained the single crystals of the radical cation salt of $\mathbf{1}^{\bullet+}$, whose torsion angles were decreased compared to those of the neutral state.
\end{abstract}

Phenothiazine derivatives are an important class of $\pi$-electron donors because of their low oxidation potentials and high stability of oxidized species, and have been utilized as the redox-active units or spin sources in studies of organic mixed-valence systems and molecular magnetism. To date, various kinds of phenothiazine oligomers connected through different bridging units have been synthesized and the electronic properties depending on the bridging unit have been investigated. ${ }^{1-4}$ In particular, directly connected phenothiazine oligomers, which are the simplest multi-redox systems consisting of phenothiazines, have been of interest in the studies of electronic and magnetic interactions among the phenothiazine units. ${ }^{5-11}$ Another important feature of phenothiazines is the controllability of the structure by redox stimuli. Phenothiazine derivatives possess a bent structure along the $\mathrm{S}-\mathrm{N}$ axis with the bending angle (denoted as $\theta_{\mathrm{b}}$ ) of typically $150-160^{\circ}$, and upon oxidation, the phenothiazine skeleton transforms to the more planar structure. ${ }^{2,8}$ Therefore, phenothiazines are potential components of redox-active molecular machines. ${ }^{12}$

Recently, we reported a novel facile synthetic method of double heterohelicenes ${ }^{13}$ by using the tandem oxidation reaction of $\mathrm{N}$-substituted heteroacenes. ${ }^{14}$ In the report, we demonstrated the preparation of two kinds of double hetero[5]helicenes from 6,13-dihydro-6,13-diazapentacene and $13 H$-dibenzo[ $b, i]$ phenoxazine via cruciform heteroacene-dimers. This protocol is considered

\footnotetext{
${ }^{a}$ Department of Molecular Engineering, Graduate School of Engineering,

Kyoto University, Kyoto 615-8510, Japan.

E-mail: sakamaki.daisuke.68u@st.kyoto-u.ac.jp, seki@moleng.kyoto-u.ac.jp

${ }^{b}$ Department of Molecular Design and Engineering, Graduate School of Engineering, Nagoya University, Nagoya, Aichi 464-8603, Japan

$\dagger$ Electronic supplementary information (ESI) available: Synthetic procedures, and spectroscopic and computational data. CCDC 1415094-1415097. For ESI and crystallographic data in CIF or other electronic format see DOI: $10.1039 / \mathrm{c} 5 \mathrm{cc} 07680 \mathrm{c}$
}

to be versatile approach to obtain double helicenes from other heteroacenes having a NH group. In this study, we applied this strategy to the construction of a novel double hetero[4]helicene by using phenothiazines as building blocks.

At first, phenothiazine-dimers were synthesized with a single $\mathrm{C}-\mathrm{N}$ connection by the already reported dimerization reaction of phenothiazines using a mixture of dimethylsulfoxide (DMSO) and acetic anhydride as the oxidant. ${ }^{5}$ In this work, we used 3,7-di-tert-butylphenothiazine (3) as the starting material to prevent the reaction on the most reactive 3 and 7 positions, and obtained the desired 1,10'-dimer in 65\% yield. However, this reaction requires a long reaction time (about a week). Next, the dimerization of 3 was examined by DDQ oxidation according to our previous work. ${ }^{14}$ This approach further improved the yield of 2 up to $78 \%$, as well as provided a short reaction time of several hours (Scheme 1). The oxidation of 2 by a combination of DDQ and $\mathrm{Sc}(\mathrm{OTf})_{3}$ resulted in the intramolecular $\mathrm{C}-\mathrm{N}$ bond formation and gave a doubly fused phenothiazine dimer 1. Furthermore, 1 was also obtained in an one-pot manner by using the tandem oxidation of 3 with DDQ followed by DDQ/Sc(OTf) .

The structures of $\mathbf{2}$ and $\mathbf{1}$ were determined by X-ray single crystal analysis (Fig. 1). In the crystal state, 2 took a cruciform structure similar to heteropentacene dimers, ${ }^{14}$ although both of the phenothiazine units were bent along the S-N axes. As expected, 1 took a double hetero[4] helicene structure, and in a unit cell, two enantiomers $\left(\left(P, P^{\prime}\right)\right.$ - and $\left(M, M^{\prime}\right)$-isomers) existed in the ratio of $1: 1$. The torsion angles in the fjord regions (denoted as $\theta_{t}$ ) were $31.7^{\circ}$ and $39.3^{\circ}$, which were larger than those of carbo[5]helicene $\left(\mathrm{ca} .30^{\circ}\right),{ }^{15}$ reflecting the bent structure of the neutral phenothiazine molecule. The $\left(P, P^{\prime}\right)$ - and $\left(M, M^{\prime}\right)$-isomers could interconvert via an

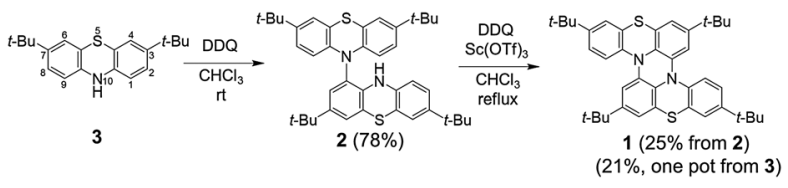

Scheme 1 Synthesis of phenothiazine dimers 1 and 2 
(a)

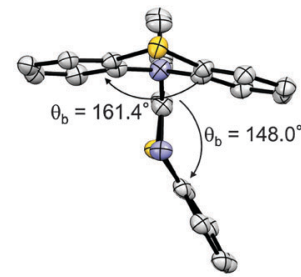

(b)

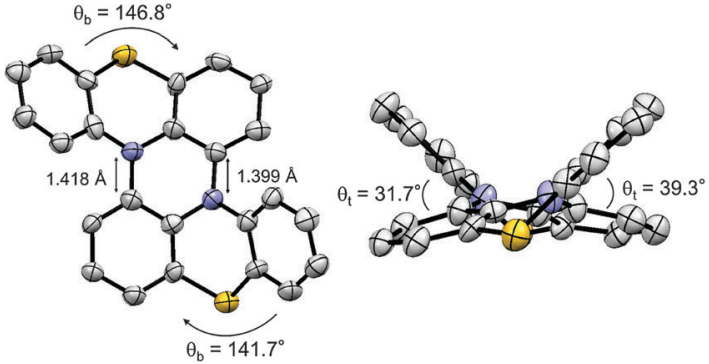

Fig. 1 X-ray structure of (a) 2 and (b) 1 . Thermal ellipsoids are set at 50\% probability. The tBu groups and hydrogen atoms were omitted for clarity.

achiral isomer (mesomer). The energy diagram of this interconversion was calculated using DFT calculations on the model compound $\mathbf{1}^{\prime}$ without $t \mathrm{Bu}$ groups at the $\mathrm{B} 3 \mathrm{LYP} / 6-31 \mathrm{G}^{*}$ level (Fig. S8, ESI $\dagger$ ). ${ }^{16}$ The step with the highest barrier is the transformation from the chiral to achiral isomers, and the barrier height was calculated to be $118.0 \mathrm{~kJ} \mathrm{~mol}^{-1}$. This value is remarkably high compared to the calculated value of dibenzo $[a, j]$ perylene, which corresponds to the all-carbon analogue of $\mathbf{1}^{\prime}\left(41.5 \mathrm{~kJ} \mathrm{~mol}^{-1}\right.$, Fig. S9, ESI $\dagger$ ), due to the bent nature of phenothiazine. ${ }^{17,18}$ In fact, we achieved the optical resolution of $\mathbf{1}$ by HPLC using a chiral stationary phase. The obtained two fractions showed mirrorimage circular dichroism (CD) spectra (Fig. 2). Spectral simulations based on time-dependent DFT (TD-DFT) calculations predicted the faster eluting fraction as the $\left(P, P^{\prime}\right)$-isomer, and the slower one as the $\left(M, M^{\prime}\right)$-isomer, respectively (Fig. S20, ESI $\dagger$ ). The decay of the CD spectra of $\mathbf{1}$ obeyed first-order kinetics, and

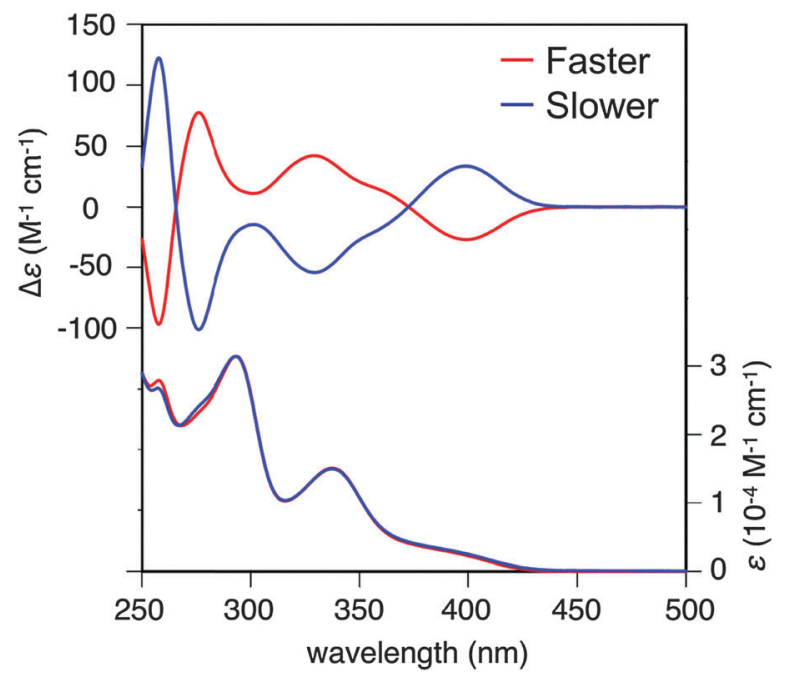

Fig. $2 \mathrm{CD}$ and absorption spectra of the faster and the more slowly eluting enantiomers of 1 in $\mathrm{CH}_{2} \mathrm{Cl}_{2}$ at $298 \mathrm{~K}$.

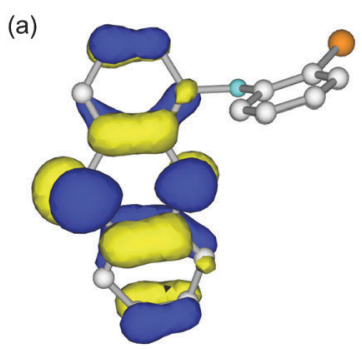

(HO-1)MO (-5.204 eV)

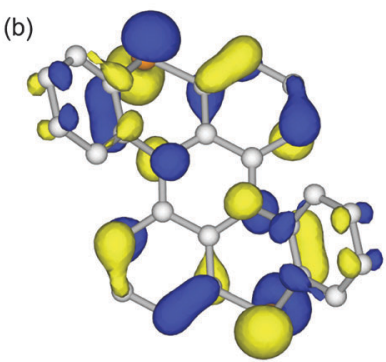

(HO-1)MO (-5.385 eV)

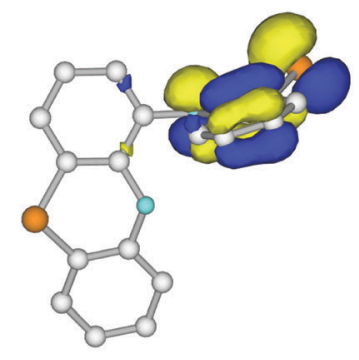

HOMO (-5.079 eV)

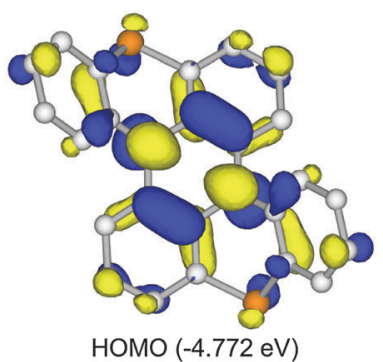

Fig. 3 Frontier Kohn-Sham MOs of (a) $\mathbf{2}^{\prime}$ and (b) $\mathbf{1}^{\prime}$ at the B3LYP/6-31G* level.

the racemization barrier was determined to be $112.8 \mathrm{~kJ} \mathrm{~mol}^{-1}$ by the Arrhenius plot of the rate constants at $30,40,50$, and $60{ }^{\circ} \mathrm{C}$ (Fig. S7, ESI $\dagger$ ). This value was in good accordance with the theoretical calculations, and higher than that of carbo[5]helicene $\left(101 \mathrm{~kJ} \mathrm{~mol}^{-1}\right) .{ }^{19}$ We also carried out the theoretical calculations for the analogues of $\mathbf{1}$ having $\mathrm{O}$ and Se instead of $\mathrm{S}$ atoms, and found that the analogue with heavier chalcogen atoms has larger torsion angles and a higher inversion barrier (Fig. S10 and S11, ESI $\dagger$ ).

Because 1 and $\mathbf{2}$ are regarded as dual-electron donor molecules, herein we focus on HOMO and (HO-1)MO. For $2^{\prime}$, HOMO and (HO-1)MO were energetically close with an energy gap of $0.125 \mathrm{eV}$ and completely localized on one side of the two phenothiazine units, resulted from their perpendicular connection (Fig. 3a). On the other hand, for $\mathbf{1}^{\prime}$, HOMO and (HO-1)MO were totally delocalized over the whole molecular skeleton, and the energy gap between these two MOs was increased to $0.613 \mathrm{eV}$ (Fig. 3b).

The redox properties of $\mathbf{1}$ and $\mathbf{2}$ were investigated via cyclic voltammetry measurements (Fig. S13, ESI $\dagger$ ) ${ }^{20}$ For 2 , the consecutive oxidation processes of $E_{1}=0.187 \mathrm{~V}$ and $E_{2}=0.296 \mathrm{~V}$ ( $v s$. ferrocene/ ferrocenium) were observed, and the potential difference $\Delta E=E_{2}-E_{1}$ was only $0.109 \mathrm{~V}$, stemming from little electronic communication between two phenothiazine moieties of 2. For 1, on the other hand, the potentials of $E_{1}(0.023 \mathrm{~V})$ and $E_{2}(0.655 \mathrm{~V})$ markedly separated and $\Delta E$ was significantly increased to $0.632 \mathrm{~V}$. This large $\Delta E$ value clearly indicates the increased electronic communication between two phenothiazine moieties in $\mathbf{1}$ by ring-fusion. The $E_{1}$ value of 1 was lower than that of 2 by $0.164 \mathrm{~V}$, suggesting the good electron donor properties of $\mathbf{1}$.

The UV-Vis-NIR absorption spectral changes of $\mathbf{1}$ during electrochemical oxidation were measured (Fig. 4). Upon oxidation, a low energy absorption band with a peak top at $0.83 \mathrm{eV}$ $(1500 \mathrm{~nm})$ appeared, in addition to the band at $2.28 \mathrm{eV}$ $(545 \mathrm{~nm})$ corresponding to the absorption of the radical cation 
(a)

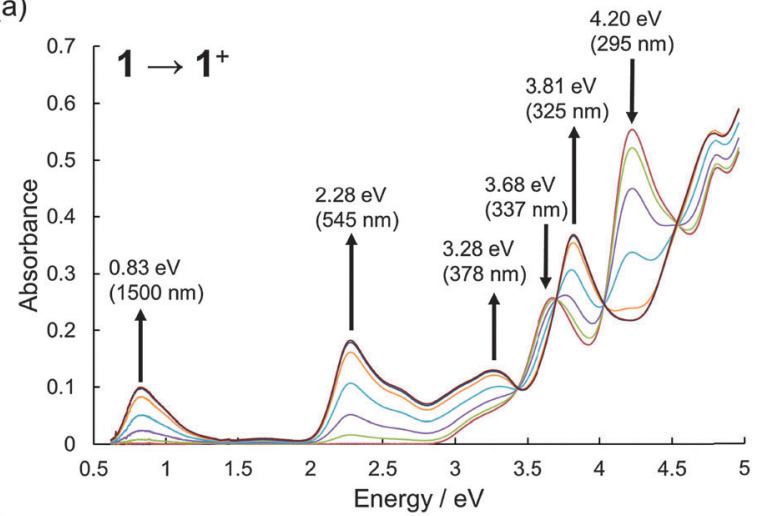

(b)

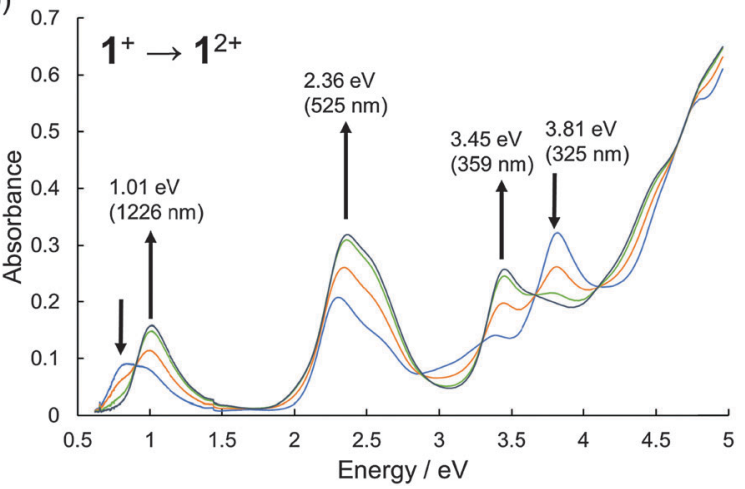

Fig. 4 UV-Vis-NIR absorption spectra during the electrochemical oxidation of 1 . (a) 1 to $1^{{ }^{+}}$and (b) $\mathbf{1}^{\bullet+}$ to $\mathbf{1}^{2+}$. The spectra were measured in $\mathrm{CH}_{2} \mathrm{Cl}_{2}$ with $0.1 \mathrm{Mn}-\mathrm{Bu}_{4} \mathrm{NBF}_{4}$ at $298 \mathrm{~K}$.

of phenothiazines. ${ }^{8,21}$ The low energy band in the NIR region could be ascribed to the charge-resonance band between two fused phenothiazine units, judging from the TD-DFT calculations of $\mathbf{1}^{\mathbf{1 0 +}}$ (Fig. S16, ESI $\dagger$ ). ${ }^{22}$ By applying higher voltage, the spectral shape was continuously changed with isosbestic points, according to the simple 1 electron oxidation process from $\mathbf{1}^{\bullet+}$ to $\mathbf{1}^{2+}$ without the formation of any significant byproducts.

Motivated by the results of electrochemical measurements, we tried to isolate cation salts of $\mathbf{1}$ and $\mathbf{2}$ by chemical oxidation. The single crystals of a radical cation salt of $\mathbf{1}^{{ }^{+}}$was obtained as red-purple needles by slow evaporation of a $\mathrm{CH}_{2} \mathrm{Cl}_{2} /$ hexane solution of 1 oxidized with 1 equiv. of tris(4-bromophenyl) aminium hexachloroantimonate (magic blue). The X-ray crystal analysis revealed the structure of $\mathbf{1}^{\boldsymbol{0}^{+}}$(Fig. 5). The dihedral angles in the fjord regions of $\mathbf{1}^{\mathbf{}}$ were smaller compared with those of the neutral 1 . This shrinkage of the helical pitches are ascribed to the increase of planarity of two phenothiazine units upon oxidation. ${ }^{17,18}$ The average length of the two C-N bonds connecting two phenothiazine moieties also became shorter than that of $\mathbf{1}$. In the crystal of $\mathbf{1}^{\mathbf{}} \mathrm{SbCl}_{6}{ }^{-}$, a $\mathrm{SbCl}_{6}{ }^{-}$anion existed on a saddle-shaped $\mathbf{1}^{++}$, as shown in Fig. $5 \mathrm{c}$. The radical cation $\mathbf{1}^{\mathbf{0}^{+}}$is stable under ambient conditions both in the solution and the solid state, and the absorption spectrum of the $\mathrm{CH}_{2} \mathrm{Cl}_{2}$ solution remained unchanged after 2 weeks under air and room light (Fig. S17, ESI $\dagger$ ). The ESR spectrum of $\mathbf{1}^{\bullet+}$ in $\mathrm{CH}_{2} \mathrm{Cl}_{2}$ at $298 \mathrm{~K}$ showed a five-line splitting, which is mainly
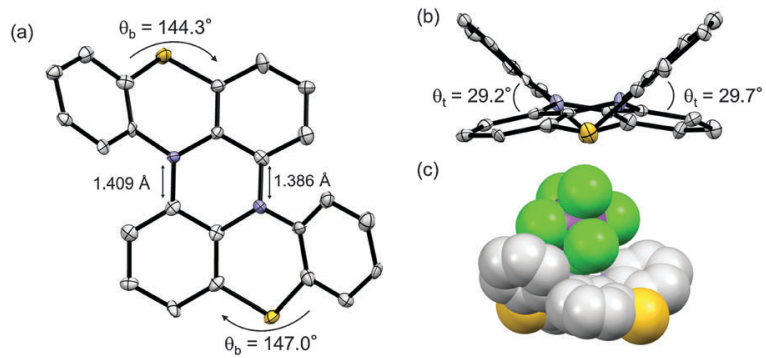

Fig. $5 \mathrm{X}$-ray structure of $\mathbf{1}^{\mathbf{}+} \mathrm{SbCl}_{6}{ }^{-}$. (a) Top view and (b) side view of $\mathbf{1}^{\mathbf{}}$. (c) Space-filling representation of $\mathbf{1}^{\cdot+} \mathrm{SbCl}_{6}{ }^{-}$. Thermal ellipsoids are set at $50 \%$ probability. The $\mathrm{tBu}$ groups and hydrogen atoms were omitted for clarity.

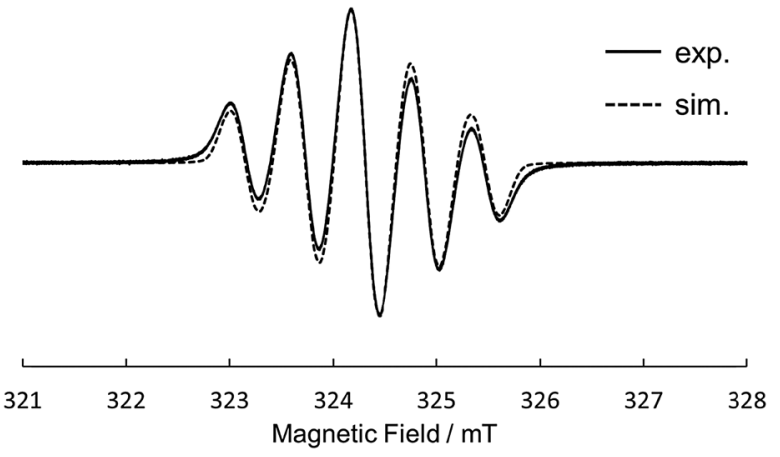

Fig. 6 ESR spectrum of $\mathbf{1}^{\bullet+}(g=2.0038)$ in $\mathrm{CH}_{2} \mathrm{Cl}_{2}$ at $298 \mathrm{~K}$.

attributed to the hyperfine coupling interactions from two equivalent nitrogen nuclei $\left(\left|a_{\mathrm{N}}\right|=0.58 \mathrm{mT}\right)$ (Fig. 6). This result indicates that the generated radical spin is equally delocalized over the two phenothiazine moieties. Oxidation of 1 with more than 2 equiv. of magic blue did not give the crystals of $\mathbf{1}^{2+}\left[\mathrm{SbCl}_{6}{ }^{-}\right]_{2}$, because of the high second oxidation potential of $\mathbf{1}$ comparable to the formal potential of magic blue. ${ }^{23}$ For 2 , the chemical oxidation with magic blue gave the crystals of doubly oxidized species, $2^{2+}\left[\mathrm{SbCl}_{6}{ }^{-}\right]_{2}$, even when treated with 1 equiv. of oxidant because of the disproportionation reaction. The structure of $2^{2+}$ was also shown by the X-ray analysis (Fig. S14, ESI $\dagger$ ). The dication $2^{2+}$ maintained a cruciform orientation, and both the two phenothiazine moieties took more planar structure compared to the neutral 2 .

In summary, we have synthesized for the first time the doubly fused phenothiazine dimer $\mathbf{1}$ with a double hetero[4]helicene structure by using the tandem oxidation of the phenothiazine derivative via the singly connected dimer 2. Although double[4] helicenes usually racemize quickly, the enantiomers of $\mathbf{1}$ were much more stable toward racemization stemming from the highly bent structure of phenothiazine. Both $\mathbf{1}$ and $\mathbf{2}$ exhibited good electron donor properties, and the chemical oxidation of these dimers gave the radical cations stable enough to be isolated. X-ray single-crystal analysis clarified the structures of $\mathbf{1}^{\mathbf{}}$ and $\mathbf{2}^{2+}$. The torsion angles in the fjord regions of $\mathbf{1}^{\mathbf{}}+$ were found to be decreased compared with those in the neutral state. The generated spin of $\mathbf{1}^{\mathbf{}+}$ was fully delocalized over the double[4] helicene skeleton. Further studies on analogues of $\mathbf{1}$ with other heteroatoms are currently underway. 
We are deeply thankful to Dr Nobuko Kanehisa (Osaka University) for her help with single-crystal X-ray analyses. This work was partly supported by a Grant-in-Aid for Young Scientists (B) (26810023) from the Japan Society for the Promotion of Science (JSPS) and by the Nanotechnology Platform Program (Molecule and Material Synthesis) of the Ministry of Education, Culture, Sports, Science and Technology, Japan. D.S. thanks the JSPS Research Fellowship for Young Scientists. The theoretical calculations were performed using the Supercomputer System of Kyoto University and the Research Center for Computational Science in Okazaki (Japan).

\section{Notes and references}

1 (a) K. Okada, T. Imakura, M. Oda, H. Murai and M. Baumgarten, J. Am. Chem. Soc., 1996, 118, 3047; (b) K. Okada, T. Imakura, M. Oda, A. Kajiwara, M. Kamachi, K. Sato, D. Shiomi, T. Takui, K. Itoh, L. Gherghel and M. Baumgarten, J. Chem. Soc., Perkin Trans. 2, 1997, 1059; (c) E. Terada, T. Okamoto, M. Kozaki, M. E. Masaki, D. Shiomi, K. Sato, T. Takui and K. Okada, J. Org. Chem., 2005, 70, 10073.

2 D. Sun, S. V. Rosokha and J. K. Kochi, J. Am. Chem. Soc., 2004, 126, 1388. 3 S. Suzuki, K. Yoshida, M. Kozaki and K. Okada, Angew. Chem., Int. Ed., 2013, 52, 2499.

4 A. C. Jahnke, M. Spulber, M. Neuburger, C. G. Palivan and O. S. Wenger, Chem. Commun., 2014, 50, 10883.

5 Y. Tsujino, Tetrahedron Lett., 1968, 9, 4111.

6 G. Cauquis, A. Deronzier and D. Serve, J. Electroanal. Chem., 1973, 47, 193.

7 C. S. Krämer, K. Zeitler and T. J. J. Müller, Tetrahedron Lett., 2001, 42, 8619.

8 T. Okamoto, M. Kuratsu, M. Kozaki, K. Hirotsu, A. Ichimura, T. Matsushita and K. Okada, Org. Lett., 2004, 6, 3493.

9 D.-M. S. Islam, Y. Sasaki, H. Kawauchi, M. Kozaki, Y. Araki, O. Ito and K. Okada, Bull. Chem. Soc. Jpn., 2008, 81, 103.

10 A. W. Franz, F. Rominger and T. J. J. Müller, J. Org. Chem., 2008, 73, 1795.
11 H. Oka, Org. Lett., 2010, 12, 448.

12 H. Kanazawa, M. Higuchi and K. Yamamoto, J. Am. Chem. Soc., 2005, $127,16404$.

13 Recent reports of the synthesis of double helicenes, see (a) K. Shiraishi, A. Rajca, M. Pink and S. Rajca, J. Am. Chem. Soc., 2005, 127, 9312; (b) Z. Wang, J. Shi, J. Wang, C. Li, X. Tian, Y. Cheng and H. Wang, Org. Lett., 2010, 12, 456; (c) J. Luo, X. Xu, R. Mao and Q. Miao, J. Am. Chem. Soc., 2012, 134, 13796; (d) X. Liu, P. Yu, L. Xu, J. Yang, J. Shi, Z. Wang, Y. Cheng and H. Wang, J. Org. Chem., 2013, 78, 6316; (e) K. Nakamura, S. Furumi, M. Takeuchi, T. Shibuya and K. Tanaka, J. Am. Chem. Soc., 2014, 136, 5555; $(f)$ S. Hashimoto, S. Nakatsuka, M. Nakamura and T. Hatakeyama, Angew. Chem., Int. Ed., 2014, 53, 14074; $(g)$ H. Kashihara, T. Asada and K. Kamikawa, Chem. - Eur. J., 2015, 21, 6523; (h) T. Fujikawa, Y. Segawa and K. Itami, J. Am. Chem. Soc., 2015, 137, 7763.

14 D. Sakamaki, D. Kumano, E. Yashima and S. Seki, Angew. Chem., Int. Ed., 2015, 54, 5404.

15 R. Kuroda, J. Chem. Soc., Perkin Trans. 2, 1982, 789.

16 All the DFT calculations in this study were carried out by using Gaussian 09 program package (Revision C.01).

17 M. Kuratsu, M. Kozaki and K. Okada, Chem. Lett., 2004, 33, 1174.

18 (a) G. Lamanna, C. Faggi, F. Gasparrini, A. Ciogli, C. Villani, P. J. Stephens, F. J. Devlin and S. Menichetti, Chem. - Eur. J., 2008, 14, 5747; (b) S. Menichetti, S. Cecchi, P. Procacci, M. Innocenti, L. Becucci, L. Franco and C. Viglianisi, Chem. Commun., 2015, $51,11452$.

19 R. H. Janke, G. Haufe, E.-U. Würthwein and J. H. Borkent, J. Am. Chem. Soc., 1996, 118, 6031.

20 Examples of the redox-active heterohelicenes, see (a) A. Rajca, M. Miyasaka, M. Pink, H. Wang and S. Rajca, J. Am. Chem. Soc., 2004, 126, 15211; (b) J. K. Zak, M. Miyasaka, S. Rajca, M. Lapkowski and A. Rajca, J. Am. Chem. Soc., 2010, 132, 3246; (c) K. Goto, R. Yamaguchi, S. Hiroto, H. Ueno, T. Kawai and H. Shinokubo, Angew. Chem., Int. Ed., 2012, 51, 10333.

21 D. W. Cho, M. Fujitsuka, A. Sugimoto, U. C. Yoon, P. S. Mariano and T. Majima, J. Phys. Chem. B, 2006, 110, 11062.

22 A. Ito, D. Sakamaki, Y. Ichikawa and K. Tanaka, Chem. Mater., 2011, 23, 841 .

23 N. G. Connelly and W. E. Geiger, Chem. Rev., 1996, 96, 877. 